Jurnal Keperawatan Silampari

Volume 2, Nomor 2, Juni 2019

e-ISSN: 2581-1975

p-ISSN: 2597-7482

DOI: https://doi.org/10.31539/jks.v2i2.651

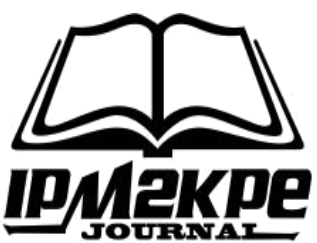

\title{
SUHU TUBUH BAYI PREMATUR DI INKUBATOR DINDING TUNGGAL DENGAN INKUBATOR DINDING TUNGGAL DISERTAI SUNGKUP
}

\author{
Padila $^{1}$, Ida Agustien ${ }^{2}$ \\ Program Studi Ilmu Keperawatan, Universitas Muhammadiyah Bengkulu ${ }^{1}$ \\ RSUP. Hasan Sadikin Bandung ${ }^{2}$ \\ padila_ahmad@yahoo.co.id ${ }^{1}$
}

\begin{abstract}
ABSTRAK
Penelitian ini bertujuan untuk membandingkan rata-rata perubahanan suhu tubuh di inkubator dinding tunggal dengan inkubator dinding tunggal disertai sungkup pada bayi prematur yang disertai hipotermi. Rancangan penelitian ini menggunakan metode deskriptif komparatif. Hasil penelitian pada kelompok bayi prematur dengan hipotermia di inkubator dinding tunggal disertai sungkup secara signifikan rata-rata perubahan suhu tubuhnya meningkat dengan nilai mean 36,09 nilai varians 0,152 adapun pada bayi prematur dengan hipotermia di inkubator dinding tunggal didapatkan nilai mean 35,35 nilai varians 0,859 dan didapatkan $t$ hitung dari kedua kelompok penelitian yaitu 2,551 dan $t$ tabel 1,717. Simpulan, inkubator dinding tunggal disertai sungkup lebih meningkatkan suhu tubuh pada bayi prematur dengan hipotermia dibandingkan inkubator dinding tunggal.
\end{abstract}

Kata Kunci: Hipotermia, Inkubator, Prematur

\section{ABSTRACT}

This study aims to compare the average change in body temperature in a single wall incubator with a single wall incubator with hood in preterm infants with hypothermia. The design of this study uses a comparative descriptive method. The results of the study in the group of preterm infants with hypothermia in a single wall incubator with a lid significantly increased mean body temperature changes with a mean value of 36.09 variance 0.152 while for preterm infants with hypothermia in a single wall incubator a mean value of 35.35 variance values 0.859 and obtained $t$ count from the two study groups namely 2.551 and 1.717 t table. In conclusion, a single wall incubator with a lid increases body temperature in premature infants with hypothermia compared to a single wall incubator.

Keywords: Hypothermia, Incubator, Premature 


\section{PENDAHULUAN}

Periode neonatus (bayi dari lahir sampai dengan usia 28 hari) merupakan tahapan yang kritis dalam siklus kehidupan bayi. Hal ini disebabkan karena resiko kematiannya yang tinggi. Riset Kesehatan Dasar tahun 2013 melaporkan bahwa 78,5\% angka kematian neonatus terjadi pada usia 0-6 hari dan 32,4\% nya disebabkan kelahiran prematur (Badan Penelitian dan Pengembangan Kesehatan, 2008).

Bayi prematur yaitu bayi yang lahir sebelum akhir usia gestasi 37 minggu, tanpa memperhitungkan berat badan lahir (Wong dkk, 2009). Semakin prematur seorang bayi maka semakin besar risiko kematiannya. Salah satu penyebab kematian pada bayi prematur disebabkan karena hipotermia (7\%) (Riskesdas, 2013). Oleh sebab itu neonatus prematur harus mendapatkan perawatan inkubator di rumah sakit (Gomella, 2009).

Hipotermia dapat disebabkan oleh karena terpapar dengan lingkungan yang dingin (suhu lingkungan rendah, permukaan yang dingin atau basah) atau bayi dalam keadaan basah atau tidak berpakaian. Hipotermia paling rentan pada bayi yang menjalani resusitasi lama, bayi yang mengalami sakit (sepsis dan penyakit lainnya), bayi dengan kelainan bawaan khususnya dengan penutupan kulit yang tidak sempurna, seperti pada meningomielokel, omfalokel, gasroskisis dan bayi dengan prematur. Menurut Usman dkk, (2008) bayi prematur dapat dengan mudah terjadinya hipotermia disebabkan karena lemak subkutan sedikit, tingginya rasio luas permukaan tubuh di bandingkan berat badan, serta kurangnya timbunan lemak.

Rerata bayi yang di rawat di ruang NICU dengan prematur selain mengalami gangguan pernafasan paling sering di ikuti dengan gangguan termoregulasi yaitu hipotermia. Dari data yang diperoleh pada bulan januari-juni 2017 ditemukan sebanyak 60 bayi prematur yang masuk ke ruang NICU dengan hipotermia. Menurut Saifuddin (2007) bahwa bayi prematur mempunyai kebutuhan khusus dalam mempertahankan dan meningkatkan kesehatan. Pemenuhan kebutuhan dasar tersebut tergantung pada pemberi asuhan. Cara pencegahan hipotermia yang dilakukan di ruang NICU yaitu dengan perawatan inkubator.

Inkubator merupakan alat dapat terbuat dari bahan yang sederhana sampai bahan campuran yaitu mulai dari kayu, bahan metal, besi atau bahan plexiglass. Dirancang sedemikian rupa sehingga dapat menciptakan kondisi optimal dalam hal suhu, kelembaban, kelancaran pemberian oksigen, dan cairan untuk kelangsungan hidup seorang bayi. Pengertian lain dari inkubator adalah alat yang dapat mempertahankan suhu lingkungan dalam keadaan optimal sesuai dengan kondisi dalam kandungan ibu yang dapat melindungi dari perubahan suhu lingkungan, sistem metabolisme, respirasi, terhindar dari infeksi dan bayi merasa aman nyaman didalamnya (Winarti, 2004).

Wiley (2010) dalam penelitiannya membandingkan pengontrolan suhu tubuh pada bayi yang di rawat di inkubator dinding tunggal dan bayi yang di rawat di inkubator dinding ganda. Dihasilkan bahwa inkubator dinding ganda lebih meningkatkan suhu tubuh bayi prematur di banding inkubator dinding tunggal. Laroia dkk, (2007) membandingkan stabilisasi suhu tubuh pada bayi yang di rawat di inkubator dinding tunggal dan bayi yang di rawat di inkubator dinding tunggal disertai sungkup, dihasilkan bahwa pada inkubator dinding tunggal lebih meningkatkan suhu tubuh pada bayi prematur dengan hipotermia dibandingkan inkubator dinding tunggal disertai sungkup.

Penelitian selanjutnya dilakukan oleh Orzalesi (2010) yaitu membandingkan stabilisasi suhu tubuh pada bayi prematur yang di rawat di inkubator dinding ganda 
dengan bayi yang di rawat di inkubator dinding tunggal disertai micro climate headbox/sungkup dihasilkan bahwa inkubator dinding tunggal disertai sungkup lebih meningkatkan suhu tubuh bayi prematur dengan hipotermia dibanding inkubator dinding tunggal. Penelitian selanjutnya yaitu membandingkan stabilisasi suhu tubuh pada bayi prematur dengan hipotermia yang di rawat di inkubator dinding tunggal dengan bayi yang di rawat di inkubator dinding tunggal disertai sungkup dihasilkan bahwa inkubator dinding tunggal disertai sungkup lebih meningkatkan suhu tubuh bayi prematur dengan hipotermia dibanding inkubator dinding tunggal.

Kesimpulan yang diambil oleh Orzalesi dalam kedua penelitiannya bahwa inkubator dinding tunggal disertai sungkup, untuk kerugian akibat konduksi (proses kehilangan panas melalui kontak benda padat) dapat diabaikan, kerugian oleh konveksi (proses kehilangan panas melalui kontak dengan aliran udara) dapat diminimalkan, tingkat kelembaban bisa mencapai 70\% ( kelembaban relatif antara 40-50\%, sementara idealnya tidak $<60 \%$ ), penggunaan udara dan oksigen yang lebih efisien ( saturasi oksigen diatas $90 \%$ ), biaya yang murah, fleksibel dalam penggunaannya sehingga bisa diletakan dan diambil sesuai kebutuhan.

Namun saat ini belum ada penelitian mengenai rata-rata perubahan suhu tubuh pada bayi prematur dengan hipotermia di inkubator dinding tunggal dan inkubator dinding tunggal disertai sungkup serta belum adanya SOP (Standar Operational Procedure) mengenai jenis inkubator manakah yang lebih baik digunakan dalam meningkatkan suhu tubuh pada bayi prematur dengan hipotermia, apakah di inkubator dinding tunggal atau inkubator dinding tunggal disertai sungkup. Maka perlu dilakukan penelitian tentang rata-rata perubahan kenaikan suhu tubuh bayi prematur dengan hipotermia pada kedua inkubator tersebut.

\section{METODE PENELITIAN}

Jenis penelitian yang digunakan adalah deskriptif komparatif. Dalam penelitian ini peneliti membagi 2 kelompok responden dan selanjutnya membandingkannya, yaitu responden dengan rata-rata perubahan suhu tubuh di inkubator dinding tunggal (Kelompok A) dengan rata-rata perubahan suhu tubuh di inkubator dinding tunggal disertai sungkup (Kelompok B) pada bayi prematur di ruang NICU mulai NovemberDesember di RSUP Dr. Hasan Sadikin Bandung 2015.

Variabel independent/bebas dalam penelitian ini adalah bayi prematur dalam inkubator dinding tunggal dan bayi prematur di inkubator dinding tunggal disertai sungkup sedangkan variable dependent/terikat adalah rata-rata perubahan suhu.

Pada penelitian ini peneliti akan membandingkan ketepatan rata-rata perubahan suhu tubuh dengan cara observasi pada bayi prematur dengan hipotermia di inkubator dinding tunggal (Kelompok A) maupun rata-rata perubahan suhu tubuh bayi prematur dengan hipotermia di inkubator dinding tunggal disertai sungkup (Kelompok B). Berdasarkan karakteristik dari skala pengukurannya maka data hasil penelitian tersebut merupakan skala interval. Penelitian dilakukan pada 24 bayi prematur yang dibagi menjadi 2 kelompok. Tiap kelompok berjumlah 12 bayi prematur yang dilahirkan dengan usia gestasi 30-37 minggu dengan BBL 1000-1900 gram. Setelah tindakan dilihat rata-rata suhu yang dihitung dari suhu ke-1 adalah suhu 15 menit saat dilakukan tindakan, ke-2 adalah 30 menit, ke-3 adalah 45 menit, ke-4 adalah 1 jam dan selanjutnya dilakukan sampai 2 jam. Penelitian dilakukan dengan menggunakan instrument penelitian berupa lembar observasi. 


\section{HASIL PENELITIAN}

Tabel. 1

Distribusi Frekuensi Karakteristik Bayi Prematur dengan Inkubator Dinding Tunggal $(\mathrm{N}=12)$

\begin{tabular}{lccc}
\hline & KARAKTERISTIK & $\mathrm{F}$ & $\%$ \\
\hline Jenis kelamin & $\mathrm{P}$ & 6 & $50 \%$ \\
\multirow{3}{*}{ BB lahir } & $\mathrm{L}$ & 6 & $50 \%$ \\
Prematuritas & BBLR & 12 & $100 \%$ \\
& Sangat Prematur $(24-30 \mathrm{mg})$ & 1 & $8.33 \%$ \\
Hipotermi & Prematur sedang (31-36 mg) & 11 & $91.67 \%$ \\
& Berat & 0 & $0 \%$ \\
& Sedang & 12 & $100 \%$ \\
\hline
\end{tabular}

Data dari tabel 1 dan tabel 2 diperoleh data bahwa sebagian besar usia kehamilan pada bayi di inkubator dinding tunggal yaitu antara 31-36 mg tergolong ke dalam prematur sedang (91.67\%), berat badan bayi antara 1000-1850 gram dan suhu rata-rata $35,35^{\circ} \mathrm{C}$, termasuk ke dalam jenis hipotermia sedang.

Tabel. 2

Distribusi Suhu Bayi prematur Dalam Inkubator Dinding Tunggal $(\mathrm{N}=12)$

\begin{tabular}{|c|c|c|c|c|c|c|c|c|c|c|c|}
\hline \multirow[b]{2}{*}{ No } & \multirow{2}{*}{$\begin{array}{c}\text { Usia } \\
\text { gestasi } \\
(\text { minggu })\end{array}$} & \multirow{2}{*}{$\begin{array}{c}\text { Berat } \\
\text { badan } \\
\text { lahir } \\
\text { (gram) }\end{array}$} & \multicolumn{8}{|c|}{ Suhu Bayi per 15 menit $\left({ }^{0} \mathrm{C}\right)$} & \multirow{2}{*}{$\begin{array}{l}\text { Rata- } \\
\text { rata } \\
\left({ }^{0} \mathrm{C}\right)\end{array}$} \\
\hline & & & 1 & 2 & 3 & 4 & 5 & 6 & 7 & 8 & \\
\hline 1 & 36 & 1200 & 36,0 & 36,1 & 36,3 & 35,0 & 36,3 & 36,6 & 36,6 & 36,6 & 36.188 \\
\hline 2 & 32 & 1400 & 34,1 & 35,0 & 35,4 & 35,4 & 35,4 & 36,1 & 35,4 & 36,4 & 35.400 \\
\hline 3 & 36 & 1500 & 34,1 & 34,1 & 34,1 & 35,2 & 35,4 & 36,1 & 36,2 & 36,2 & 35.175 \\
\hline 4 & 31 & 1850 & 35,5 & 35,9 & 36,0 & 35,7 & 35,9 & 35,8 & 35,8 & 35,8 & 35.800 \\
\hline 5 & 32 & 1550 & 34,1 & 35,4 & 35,6 & 35,8 & 33,4 & 35,2 & 35,8 & 36,2 & 35.188 \\
\hline 6 & 32 & 1400 & 32,0 & 32,0 & 32,1 & 33,1 & 32,2 & 33,2 & 33,2 & 33,6 & 32.675 \\
\hline 7 & 34 & 1000 & 35,4 & 35,4 & 36,2 & 36,1 & 36,1 & 36,2 & 36,2 & 36,2 & 35.975 \\
\hline 8 & 32 & 1600 & 36,0 & 36,1 & 36,0 & 35,9 & 35,8 & 35,3 & 35,3 & 35,4 & 35.725 \\
\hline 9 & 33 & 1000 & 36,0 & 36,0 & 35,9 & 35,8 & 35,8 & 35,7 & 35,7 & 35,7 & 35.825 \\
\hline 10 & 36 & 1250 & 35,7 & 35,7 & 35,6 & 35,6 & 35,6 & 35,6 & 35,6 & 35,6 & 35.625 \\
\hline 11 & 30 & 1500 & 33,6 & 33,6 & 33,8 & 34,5 & 35,7 & 35,7 & 35,9 & 36,1 & 34.863 \\
\hline 12 & 36 & 1400 & 35,5 & 33,0 & 36,1 & 36,1 & 36,5 & 36,5 & 36,5 & 36,7 & 35.863 \\
\hline & & & & & & & & & & & 35,35 \\
\hline
\end{tabular}

Berdasarkan tabel 2, rerata Suhu Bayi prematur Dalam Inkubator Dinding Tunggal $(\mathrm{N}=12)$ bernilai $35,35{ }^{\circ} \mathrm{C}$.

Tabel. 3

Distribusi Frekuensi Karakteristik Bayi Prematur dengan Inkubator Dinding Tunggal + Sungkup $(N=12)$

\begin{tabular}{cllc}
\hline Karakteristik & & $\mathrm{F}$ & $\%$ \\
\hline Jenis kelamin & $\mathrm{P}$ & 5 & $38.46 \%$ \\
& $\mathrm{~L}$ & 7 & $61.54 \%$
\end{tabular}




\begin{tabular}{lccc} 
BB lahir & BBLR & 12 & $100 \%$ \\
Prematuritas & $\begin{array}{c}\text { Sangat } \\
\text { Prematur } \\
(24-30 \mathrm{mg})\end{array}$ & 2 & $16.67 \%$ \\
& $\begin{array}{c}\text { Prematur } \\
\text { sedang } \\
\text { Hipotermi }\end{array}$ & 10 & $83.33 \%$ \\
& $\begin{array}{l}(31-36 \mathrm{mg}) \\
\text { Berat }\end{array}$ & 0 & $0 \%$ \\
& Sedang & 11 & $91.67 \%$ \\
& Ringan & 1 & $8.33 \%$ \\
\hline
\end{tabular}

Dari data tabel 3 diperoleh data bahwa sebagian besar usia kehamilan pada bayi di inkubator dinding tunggal+sungkup yaitu antara 31-36 mg tergolong ke dalam prematur sedang $(83.33 \%)$, berat badan bayi antara 1000-1950 gram dan suhu rata-rata $36,09^{\circ} \mathrm{C}$ dan termasuk ke dalam jenis hipotermia sedang.

Tabel. 4

Distribusi Suhu Bayi prematur dalam Inkubator Dinding Tunggal+Sungkup $(\mathrm{N}=12)$

\begin{tabular}{|c|c|c|c|c|c|c|c|c|c|c|c|}
\hline \multirow[b]{2}{*}{ No } & \multirow{2}{*}{$\begin{array}{c}\text { Usia } \\
\text { gestasi } \\
\text { (minggu) }\end{array}$} & \multicolumn{10}{|c|}{ Suhu Bayi per 15 menit $\left({ }^{0} \mathrm{C}\right)$} \\
\hline & & $\begin{array}{l}\text { badan } \\
\text { lahir } \\
\text { (gram) }\end{array}$ & 1 & 2 & 3 & 4 & 5 & 6 & 7 & 8 & $\begin{array}{l}\text { rata } \\
\left({ }^{0} \mathrm{C}\right)\end{array}$ \\
\hline 1 & 32 & 1200 & 34,4 & 35,5 & 35,6 & 36 & 36,0 & 36,5 & 36,6 & 36,5 & 35.888 \\
\hline 2 & 36 & 1800 & 35,4 & 35,1 & 36,5 & 36,5 & 36,6 & 36,7 & 36,7 & 36,8 & 36.288 \\
\hline 3 & 33 & 1250 & 35,8 & 35,9 & 36,1 & 36,2 & 36,3 & 36,4 & 36,5 & 36,6 & 36.225 \\
\hline 4 & 30 & 1430 & 35,1 & 36,1 & 36,1 & 36,4 & 36.8 & 36.1 & 36.4 & 36,5 & 36.188 \\
\hline 5 & 30 & 1150 & 35,8 & 35,9 & 36,1 & 36,2 & 36,5 & 36,2 & 35,8 & 36,5 & 36.125 \\
\hline 6 & 36 & 1950 & 33,0 & 33,9 & 34,5 & 34,8 & 35,8 & 36,2 & 36.8 & 36,6 & 35.200 \\
\hline 7 & 33 & 1300 & 35,7 & 36,2 & 36,6 & 36,8 & 36,9 & 36,6 & 36,7 & 36,7 & 36.525 \\
\hline 8 & 32 & 1450 & 36,0 & 36,4 & 36,6 & 36,8 & 36,8 & 36,9 & 36,9 & 37,1 & 36.688 \\
\hline 9 & 32 & 1700 & 35,0 & 35,6 & 36,2 & 36,7 & 36,5 & 36,7 & 36,8 & 36,9 & 36.300 \\
\hline 10 & 34 & 1200 & 34,0 & 34,8 & 35,8 & 36,2 & 36,8 & 36,9 & 36.9 & 37,0 & 36.050 \\
\hline 11 & 36 & 1000 & 35,0 & 35,9 & 36,0 & 36,0 & 36,4 & 36,6 & 36,0 & 36,4 & 36.038 \\
\hline 12 & 34 & 1100 & 34,5 & 34,7 & 35,1 & 35,6 & 36,0 & 36,3 & 36,6 & 36,6 & $\begin{array}{l}35.675 \\
36,09\end{array}$ \\
\hline
\end{tabular}

Berdasarkan tabel 4, rerata Suhu Bayi prematur Dalam Inkubator Dinding Tunggal plus sungkup $(\mathrm{N}=12)$ bernilai $36,09{ }^{\circ} \mathrm{C}$.

\section{Analisis Bivariat}

Tabel. 5

Distribusi Rata-Rata Kenaikan Suhu Bayi Prematur yang dirawat dalam Inkubator Dinding Tunggal+Sungkup dan Inkubator Dinding Tunggal Saja

\begin{tabular}{|c|c|c|c|c|}
\hline Tipe Inkubator & $\bar{X}$ & Varians $\left(\mathrm{S}^{2}\right)$ & t Hitung & $\mathrm{t}$ Tabel \\
\hline & Mean $\left({ }^{0} \mathrm{C}\right)$ & & & \\
\hline $\begin{array}{l}\text { Inkubator Dinding } \\
\text { Tunggal + Sungkup }\end{array}$ & 36,09 & 0.152 & \multirow[t]{2}{*}{2,551} & \multirow[t]{2}{*}{1,717} \\
\hline $\begin{array}{l}\text { Inkubator Dinding } \\
\text { Tunggal }\end{array}$ & 35,35 & 0.859 & & \\
\hline
\end{tabular}


Dalam hal ini berarti t Test > t Tabel, maka dapat disimpulkan bahwa terdapat perbedaan yang signifikan antara bayi prematur yang mengalami hipotermi yang mendapat perawatan inkubator diding tunggal+sungkup dengan inkubator tunggal saja. Hal yang menunjang adalah Hasil penelitian rata-rata perubahan suhu tubuh pada kelompok A (Inkubator dinding tunggal+sungkup) menunjukan suhu rata-rata setelah perawatan 2 jam yaitu 36,09 dengan nilai varians 0,152 . Sedangkan pada kelompok B (Inkubator dinding tunggal) diperoleh suhu rata-rata 35,35 dengan nilai varians 0,859 melalui uji $\mathrm{T}$ di dapatkan nilai t lebih besar dari nilai t table maka menunjukan terdapat perbedaan bermakna rata-rat perubahan suhu tubuh antara kedua kelompok.

\section{PEMBAHASAN}

Hasil rata-rata perubahan suhu pada perawatan di inkubator dinding tunggal lebih kecil dibandingkan dengan perawatan di inkubator dinding tunggal disertai sungkup. Pada inkubator dinding tunggal disertai sungkup terjadi peningkatan suhu tubuh yang signifikan tiap rentang waktu dengan interval 15 menit selama pengukuran 2 jam, sedangkan pada inkubator dinding tunggal didapatkan peningkatan rata-rata perubahan suhu tubuh yang cukup lama, jadi terlihat sekali ada perbedaan yang sangat signifikan. Hal ini di buktikan dengan suhu rata-rata setelah dilakukan perawatan selama 2 jam dengan interval setiap 15 menit pada bayi prematur dengan hipotermia di inkubator dinding tunggal disertai sungkup yaitu $36,09^{\circ} \mathrm{C}$ sedangkan suhu rata-rata setelah dilakukan perawatan selama 2 jam dengan interval setiap 15 menit pada bayi prematur di inkubator dinding tunggal yaitu $35,38^{\circ} \mathrm{C}$.Perbedaan ini sesuai dengan penelitian Orzalesi (2010) yang mengungkapkan bahwa inkubator dinding tunggal disertai sungkup lebih meningkatkan suhu tubuh bayi prematur dibandingkan inkubator dinding tunggal.

Perawatan di inkubator dinding tunggal dan di inkubator dinding tunggal disertai sungkup dapat mencegah proses kehilangan panas secara konduksi dan evaporasi. Perawatan dalam inkubator dapat mempertahankan suhu lingkungan dalam keadaan optimal sesuai dengan kondisi dalam kandungan ibu yang dapat melindungi dari perubahan suhu lingkungan, sistem metabolisme, respirasi, terhindar dari infeksi dan bayi merasa aman nyaman didalamnya (Winarti, 2004).

Prinsip kerja inkubator yaitu dengan adanya sistem sirkulasi udara, dimana udara ruangan dan oksigen bergabung masuk melalui saringan yang ada di inkubator. Adanya pemanas yang menunjukan jumlah pasokan panas yang dibutuhkan untuk mempertahankan suhu kulit bayi pada kadar yang seharusnya sehingga akan terjadi pemanasan yang tepat, kemudian di sirkulasi dengan kipas sirkulasi melalui penampung kelembaban dan di tiupkan ke dalam hood atau inkubator sehingga dihasilkan suhu dan kelembaban di atas matras.

Keuntungan dari menggunakan inkubator dinding tunggal disertai sungkup yaitu untuk kerugian akibat konduksi (proses kehilangan panas melalui kontak benda padat) dapat diabaikan, kerugian oleh konveksi (proses kehilangan panas melalui kontak dengan aliran udara) dapat diminimalkan, tingkat kelembaban bisa mencapai $70 \%$ (kelembaban relatif antara 40-50\%, sementara idealnya tidak $<60 \%$ ), penggunaan udara dan oksigen yang lebih efisien (saturasi oksigen diatas 90\%), biaya yang murah, memberikan lingkungan hangat yang konstan bahkan ketika pintu inkubator terbuka ketika melakukan tindakan, fleksibel dalam penggunaannya sehingga bisa diletakan dan diambil sesuai kebutuhan. 
Secara garis besarnya keuntungan dari perawatan inkubator dinding tunggal dan perawatan di inkubator dinding tunggal disertai sungkup yaitu: 1) Memberikan lingkungan hangat yang konstan, bahkan ketika pintu terbuka. 2) Dapat meminimalkan kehilangan air transepidermal dengan kelembaban yang relatif tinggi. 3) Dapat mengurangi kehilangan panas akibat radiasi jika bayi diselimuti Sedangkan kerugiannya adalah: 1) mengurangi akses untuk prosedur. 2) Dapat menghambat interaksi dengan orang tua. 3) bising akibat mesin inkubator dan pintu (Gomella, 2009).

Bayi yang dirawat di inkubator dinding tunggal membutuhkan waktu cukup lama dalam meningkatkan suhu tubuh, hal ini disebabkan karena inkubator dinding tunggal akan dengan mudah terjadi kehilangan panas melalui konduksi dan konveksi karena disaat pintu jendela inkubator terbuka saat memberikan tindakan akan terjadi turbulansi udara yang masuk melewati bayi tanpa adanya penghalang (Gardner, 2010).

Stress dingin yang berkepanjangan menyebabkan meningkatnya konsumsi oksigen dan penggunaan glukosa yang abnormal, sehingga menyebabkan terjadinya hipoglikemia, hipoksemia dan asidosis. Bayi yang mengalami stress nafas dan mengalami hipotermia, tidak mampu memenuhi kebutuhan oksigen yang meningkat. Hal ini dapat memperparah hipoksemia dan vasokontriksi pembuluh darah paru. Akibatnya aliran darah ke jaringan akan berkurang, terjadi metabolisme anaerob, penumpukan asam laktat dan peningkatan konsumsi oksigen.

Dari hasil observasi pada bayi prematur dengan hipotermia yang di rawat di inkubator dinding tunggal diperoleh data bahwa pada bayi prematur jenis kelamin lakilaki sebanyak $50 \%$ dan bayi perempuan $50 \%$. Sebagian besar berat badannya $<2500$ gram , panjang badan $<46 \mathrm{~cm}$, lingkar kepala $<33 \mathrm{~cm}$, lingkar dada $<30 \mathrm{~cm}$, kuku panjangnya belum melewati ujung jari, batas dahi dan rambut kepala tidak jelas,rambut lanugo masih banyak, jaringan lemak subkutan tipis atau kurang, tulang rawan daun telinga belum sempurna pertumbuhannya, tumit mengkilap, telapak kaki halus, alat kelamin pada bayi laki-laki pigmentasi dan rugae pada skrotum kurang, testis belum turun ke dalam skrotum, untuk bayi perempuan klitoris menonjol, labio minora belum tertutup oleh labio mayora, tonus otot lemah, pergerakannya lemah, jaringan kelenjar mamae masih kurang, verniks kaseosa tidak ada atau sedikit dan ditemukan sebagian besar mengalami hipotermia sedang yang ditandai dengan suhu tubuh berkisar antara $32-35,9^{\circ} \mathrm{C}$, bayinya tampak mengantuk tapi mudah untuk dibangunkan, aktifitas lemah, menangis lemah, kaki teraba dingin dan reflex menghisap lemah.

Rata-rata perubahan suhu tubuh pada bayi prematur dengan hipotermia di inkubator dinding tunggal sebagian besar mengalami peningkatan suhu tubuh yang cukup lama, aktivitas bayinya kebanyakan tertidur dan sesekali menangis jika lapar atau popoknya basah. Jadi sesuai dengan teori bahwa suhu tubuh bervariasi, saat tidur suhu rendah, saat beraktivitas seperti halnya menangis maka suhu tubuh akan naik dan dilihat dari salah satu faktor-faktor yang mempengaruhi suhu tubuh pada bayi prematur yaitu irama sirkardian. Pada umumnya suhu badan inti akan menurun selama tidur dan mencapai nilai terendah atau mencapai nilai temperatur basal tubuh saat sebelum orang bangun. Suhu tubuh secara normal akan mengalami perubahan yang bervariasi setiap hari sebesar $2,0^{\circ} \mathrm{C}$ diantara pagi dan sore hari, perubahan ini tergantung siklus tidur seseorang dan metabolisme seseorang. Suhu tubuh naik sekitar pukul 18.00 dan kemudian turun sekitar pukul 1-4 dini hari. Karena aktivitas bayi prematur di inkubator dinding tunggal sebagian besar tertidur maka potensial terjadinya suhu tubuh yang rendah. 
Pada bayi prematur dengan hipotermia di inkubator dinding tunggal yang memiliki berat badan 1000 gram untuk terjadinya kenaikan suhu tubuh, prosesnya paling lama diantara bayi prematur dengan hipotermi yang berat badan nya diatas 1000 gram hal ini disebabkan selain sedikitnya lemak subkutis ditambah bayinya di puasakan karena retensi lambungnya masih keruh. Seperti dijelaskan dalam teori bahwa pada bayi dengan gangguan malnutrisi dapat dengan mudah mengalami penurunan suhu tubuh. Gangguan malnutrisi dapat menurunkan kecepatan metabolism, hal ini terjadi karena dalam sel tidak ada zat makanan yang dibutuhkan untuk mengadakan metabolisme. Sehingga perlu penanganan cepat agar malnutrisi tidak terjadi yaitu dengan pemberian cairan dan nutrisi parenteral yang sesuai (Ganong, 1995).

Selanjutnya dari hasil observasi pada bayi prematur dengan hipotermia yang di rawat di inkubator dinding tunggal disertai sungkup diperoleh data bahwa pada bayi prematur jenis kelamin laki-laki sebanyak $61,54 \%$ dan bayi perempuan $38,46 \%$. Sebagian besar berat badannya $<2500$ gram, panjang badan $<46 \mathrm{~cm}$, lingkar kepala $<33 \mathrm{~cm}$, lingkar dada $<30 \mathrm{~cm}$, kuku panjangnya belum melewati ujung jari, batas dahi dan rambut kepala tidak jelas,rambut lanugo masih banyak, jaringan lemak subkutan tipis atau kurang, tulang rawan daun telinga belum sempurna pertumbuhannya, tumit mengkilap, telapak kaki halus, alat kelamin pada bayi laki-laki pigmentasi dan rugae pada skrotum kurang, testis belum turun ke dalam skrotum, untuk bayi perempuan klitoris menonjol, labio minora belum tertutup oleh labio mayora, tonus otot lemah, pergerakannya lemah, jaringan kelenjar mamae masih kurang, verniks kaseosa tidak ada atau sedikit dan ditemukan sebagian besar mengalami hipotermia sedang yang ditandai dengan suhu tubuh berkisar antara $32-35,9^{\circ} \mathrm{C}$, bayinya tampak mengantuk tapi mudah untuk dibangunkan, aktifitas lemah, menangis lemah, kaki teraba dingin dan reflex menghisap lemah.

Rata-rata perubahan suhu tubuh pada bayi prematur dengan hipotermia di inkubator dinding tunggal disertai sungkup sebagian besar mengalami kenaikan suhu tubuh yang sangat signifikan adapun aktivitas bayinya ada yang dalam keadaan terbangun, tidur, bahkan menangis jadi sesuai dengan teori bahwa suhu tubuh bervariasi saat tidur suhu rendah dan saat beraktivitas seperti halnya menangis maka suhu tubuh akan naik.

Bayi yang di rawat di inkubator dinding tunggal disertai sungkup sebagian ada yang sudah mendapatkan nutrisi melalui Naso Gastric Tube (NGT) dan sebagian bayi masih dipuasakan karena retensi lambungnya masih keruh. Pada bayi prematur yang sudah mendapatkan nutrisi melalui NGT yang diberikan tiap 3 jam maka pada waktu jam minum bayi akan menangis karena lapar, dan bayi juga akan mengalami stress. Saat stress tubuh akan merespon secara fisik dan emosional. Perangsangan terhadap saraf simpatis akan meningkatkan produksi epinephrin dan norepinephrin yang akan meningkatkan aktifitas metabolisme dan produksi panas dalam tubuh. Lingkungan yang bising pun akan mengakibatkan bayi stress maka untuk set alarm alat-alat di ruang neonatus suaranya harus dalam volume yang minimal. perawatan bayi di ikubator dinding tunggal disertai sungkup selain untuk meningkatkan suhu tubuh juga merupakan salah satu upaya untuk menghindari kebisingan dari lingkungan sekitar.

Bayi prematur dengan hipotermia harus segera dengan cepat ditangani maka perlu adanya peran perawat neonatus prematur dalam memberikan asuhan keperawatan yang ditunjang dengan ilmu pengetahuan, kemampuan yang terlatih. Diharapkan adanya keseragaman dari para perawat dalam penanganan hipotermia dan penggunaan inkubator yang sesuai untuk mencegah terjadinya hipotermia pada bayi prematur yaitu 
dengan menggunakan inkubator dinding tunggal disertai sungkup (Avery, B, Fletcher, A. 1999).

\section{SIMPULAN}

Berdasarkan hasil penelitian didapatkan rata-rata perubahan suhu tubuh bayi prematur dengan hipotermia yang dilakukan perawatan di inkubator dinding tunggal adalah $35,35^{\circ} \mathrm{C}$. Bayi prematur yang di rawat di inkubator dinding tunggal membutuhkan waktu cukup lama dalam meningkatkan suhu tubuh. Bayi dengan hipotermia yang berkepanjangan akan berdampak terhadap gangguan-gangguan diantaranya bisa mengakibatkan terjadinya hipoglikemia, asidosis, hipoksia dan kematian

Rata-rata perubahan suhu bayi prematur dengan hipotermia yang di lakukan perawatan di inkubator dinding tunggal disertai sungkup adalah $36,09^{\circ} \mathrm{C}$. Keuntungan yang ditimbulkan dari penggunaan inkubator dinding tunggal disertai sungkup yaitu dapat mengurangi hilangnya panas tubuh, penggunaan udara dan oksigen yang lebih efisien, memberikan lingkungan hangat yang konstan, bahkan ketika pintu terbuka selain itu biaya yang murah, fleksibel dalam penggunaannya sehingga bisa diletakan dan diambil sesuai kebutuhan.

Hasil rata-rata perubahan suhu tubuh pada bayi prematur dengan hipotermia di inkubator dinding tunggal disertai sungkup lebih tinggi dibandingkan dengan inkubator dinding tunggal.

\section{SARAN}

\section{Bagi Institusi}

Hasil penelitian ini dapat digunakan untuk menjadi rujukan dalam pengambilan keputusan dan kebijakan mengenai perawatan bayi dalam inkubator yang lebih optimal.

\section{Profesi Keperawatan}

Di harapkan ada keseragaman dari para perawat dalam penanganan hipotermia dan penggunaan inkubator yang sesuai untuk mencegah terjadinya hipotermia pada bayi prematur sehingga perlu adanya protap/SOP penggunaan inkubator dinding tunggal disertai sungkup sebagai acuan dalam melaksanakan perawatan.

\section{Institusi Pendidikan}

Penelitian ini dapat dijadikan masukan bagi institusi pendidikan, materi perawatan bayi prematur dengan hipotermia yang di rawat di inkubator dinding tunggal disertai sungkup.dapat dimasukan dalam salah satu materi pengajaran terutama tentang perawatan bayi prematur.

\section{Bagi Penelitian Selanjutnya}

Hasil penelitian ini dapat dijadikan data dasar dalam penelitian selanjutnya tentang rata-rata perubahan suhu di inkubator dinding ganda dengan inkubator dinding tunggal disertai sungkup.atau penelitian rata-rata perubahan suhu di inkubator dinding tunggal disertai sungkup dengan inkubator dinding tunggal metode sungkup konvensional. 


\section{DAFTAR PUSTAKA}

Avery, B \& Fletcher, A. (1999). Neonatology Pathophysiology Management of the Newborn. Fifth Edition. Philadelphia: Awolters Kluwer Company

Badan Penelitian dan Pengembangan Kesehatan. (2008)

Ganong, W.F. (1995). Buku Ajar Fisiologi Kedokteran: Alih Bahasa Djauhari Widjajakusumah, Dewi Irawati, Minarma Siagian, Dangsinu Moeloek, Brahm U Pendit. Jakarta: EGC

Gardner, L. S. (2010). Hand Book of Neonatal Intensive Care. Philadelphia: Mosby Company

Gomella, T. L. (2009). Neonatologi Management, Procedur, On-Call Problem Diseassea, and Drugs. Sixth Edition. North America: Mc Graw-Hill Company

Kosim, M. S., Yunanto, A., Dewi, R., Sarosa, G. I., Usman, A. (2008). Buku Ajar Neonatologi. Jakarta: Badan Penerbit IDAI, pp: 411-416

Laroia, N. (2007). Incubator Double Hood vs Incubator Double Hood with Micro Climate. Cochrane Library in the Word

Orzalesi, M. (2010). Incubator How to Choose the Best. Hali. Gineveri in the Word

Riset Kesehatan Dasar. (2013). Jakarta: Departemen Kesehatan RI

Saifuddin, A. B. (2007). Buku Acuan Nasional Pelayanan Kesehatan Maternal dan Neonatal. Jakarta: Yayasan Bina Pustaka Sarwono Prawirohardjo

Wiley, J \& Sons. (2010). Double Wall versus Single Wall Incubator. Calipornia. Cochrane Neonatal Group

Winarti, W. (2004). Mengenal Inkubator Penggunaan dan Pemeliharaan. Bandung

Wong, D L, Easton. M. H, Wilson, H, Winkelstein, M. L, and Schwartz, P. (2009). Buku Ajar Keperawatan Pediatrik: Alih Bahasa Agus Sutarna, Neti Juniarti, H.Y Kuncara. Jakarta: EGC 